\title{
Beiging Modulates Inflammatory Adipogenesis in Salt-Treated and MEK6-Transfected Adipocytes
}

\author{
Songjoo Kang ${ }^{1}$ and Myoungsook Lee ${ }^{1,2, *(\mathbb{D})}$ \\ 1 Department of Food \& Nutrition, Sungshin Women's University, Seoul 01133, Korea; crl@sungshin.ac.kr \\ 2 Research Institute of Obesity Sciences, Sungshin Women's University, Seoul 01133, Korea \\ * Correspondence: mlee@sungshin.ac.kr; Tel.: +082-02-920-7211
}

check for updates

Citation: Kang, S.; Lee, M. Beiging Modulates Inflammatory Adipogenesis in Salt-Treated and MEK6-Transfected Adipocytes. Cells 2021, 10, 1106. https://doi.org/ $10.3390 /$ cells10051106

Academic Editor: Bruce A. Bunnell

Received: 26 March 2021

Accepted: 28 April 2021

Published: 4 May 2021

Publisher's Note: MDPI stays neutral with regard to jurisdictional claims in published maps and institutional affiliations.

Copyright: (c) 2021 by the authors. Licensee MDPI, Basel, Switzerland. This article is an open access article distributed under the terms and conditions of the Creative Commons Attribution (CC BY) license (https:/ / creativecommons.org/licenses/by/ $4.0 /)$.

\begin{abstract}
To investigate whether the beiging process changes the interactive effects of salt and MEK6 gene on inflammatory adipogenesis, the salt treatment $(\mathrm{NaCl} 50 \mathrm{mM})$ and $M E K 6$ transfection of $\mathrm{Tg}^{(+/+)}$cells were performed with white adipocytes (WAT) and beige-like-adipocytes (BLA). BLA induced by T3 were confirmed by UCP-1 expression and the MEK6 protein was 3.5 times higher in MEK6 transfected WAT than the control. The adipogenic genes, PPAR- $\gamma$ and $C / E B P-\alpha$, were 1.5 times more highly expressed in the salt-treated groups than the non-salt-treated groups, and adipogenesis was greatly increased in $\mathrm{Tg}^{(+/+)}$WAT compared to non-transfected $\mathrm{Tg}^{(-/-)}$. The adipogenesis induced by salt treatment and MEK6 transfection was significantly reduced in BLA. The inflammatory adipocytokines, TNF- $\alpha$, IL- $1 \beta$, and IL- 6 , were increased in the salt-treated $\mathrm{Tg}^{(+/+)}$WAT, but an anti-inflammation biomarker, the adiponectin/leptin ratio, was reduced in $\mathrm{Tg}^{(+/+)}$, to tenth of that in $\mathrm{Tg}^{(-/-)}$. However, the production of adipocytokines in WAT was strongly weakened in BLA, although a combination of salt and MEK6 transfection had the most significant effects on inflammation in both WAT and BLA. Oxygen consumption in mitochondria was maximized in salt-treated and MEK6 transfected WAT, but it was decreased by 50\% in BLA. In conclusion, beiging controls the synergistic effects of salt and MEK6 on adipogenesis, inflammation, and energy expenditure.
\end{abstract}

Keywords: obesity; beiging; beige-like adipocyte (BLA); white adipocyte (WAT); MEK6; salt

\section{Introduction}

Various obesogenic factors, such as hormone disorder, energy-dense diets, low physical activity, and oxidative stress, may induce body fat accumulation [1-3]. We previously found that salt $(\mathrm{NaCl})$ treatment dose-dependently increased the expression of adipogenic/lipogenic genes and the production of pro-inflammatory adipocytokines in WAT [4]. Salt-loading diets ( $>15 \mathrm{~g} \mathrm{NaCl} /$ day for seven days) also induced hypoxia in human visceral adipose tissues, which is associated with changes in circulating monocyte subsets (CD14++, CD16+) related to inflammation [5]. Several mechanisms have been suggested to prove the causality in salt-induced obesity, such as monitoring signaling related to adipogenesis/lipogenesis, insulin resistance, and inflammatory environments [3-6].

The major function of brown adipose tissue in newborns and hibernating mammals is to produce heat through thermogenin, uncoupling protein-1 (UCP-1), by non- shivering thermogenesis instead of through ATP production in the mitochondria of WAT [7]. Brown adipose tissue is decreased or disappears during aging, but beige fat of WAT is sporadically generated in WAT in response to cold temperatures or hormones, which is called beiging or browning [8,9]. The mechanisms related to UCP-1 in beiging, or BLA, may be major mechanisms with which to prevent obesity $[10,11]$. The regulator of UCP-1 expression, p38, plays a role in various process, such as inflammation, apoptosis, growth, proliferation, and carcinogenesis [12]. In a pilot study, mitogen-activated protein kinase kinase 6 (MAP2K6, $M K K 6)$ or MAPK/ERK kinase 6 (MEK6) gene was screened through.

GWAS in obese children with lower resting metabolic rate (RMR) [13]. MEK6 pathways are associated with adipogenesis/lipogenesis, and the phosphorylation of p38- $\alpha$ is 
activated by cold temperatures and upstream regulators of $M E K 6$ [14]. The depression of p38- $\alpha$ and UCP-1 may decrease energy (heat) production and induce fat accumulation; however, MEK6-activated MAPK/ERK/p38 pathways inhibit beiging [15]. We also confirmed that several mechanisms of salt-induced obesity in the WAT involving MEK6 gene were also involved in energy expenditure in obese children [16,17].

Although the contributors or target factors for BAT thermogenesis are not fully understood, increasing the thermogenic capacity to prevent obesity should be considered. Because the MEK6 gene inhibits UCP-1's action in adipocytes, in this study, we planned to identify whether the beiging process changes the interactive effects of salt and MEK6-geneinduced inflammation, adipogenesis, and energy expenditure.

\section{Materials and Methods}

\subsection{Reagents and Materials}

Bovine calf serum (Thermofisher, Waltham, MA, USA), fetal bovine serum (FBS, Capricorn Scientific GmbH, Ebsdorfergrund, Germany), Dulbecco's modified Eagle's medium, penicillin-streptomycin, trypsin-EDTA (DMEM, Welgene, Deagu, Republic of Korea), insulin and dexamethasone (DEX, Sigma-Aldrich CO., St. Louis County, MN, USA) were included in the media. For cell staining, Oil Red O staining powder (Sigma-Aldrich CO., St. Louis County, MN, USA), BODIPY powder, and Nile red powder (Thermofisher, Waltham, MA, USA) were used. The MTT assay (Duchefa Biochemie, Amsterdam, The Netherland) was used to measure cell proliferation. For browning, DEX, 3-isobutyl-1-methylxanthine (IBMX), triiodothyronine $\left(\mathrm{T}_{3}\right)$, rosiglitazone were purchased from Sigma-Aldrich CO. (St. Louis County, MN, USA). For MEK6 transfection, Lipofectamine 3000 (Invitrogen, Carlsbad, CA, USA) was used. Antibodies for PPAR- $\gamma$, leptin and UCP-1 (\#204350, \#3583 and \#10983, Abcam, Cambridge, UK); C/EBP- $\alpha$ (\#600-1438, Novus Biologycals, Okay, OK, USA); vinculin and MEK-6 (\#4650 and \#5-15808, Invitrogen, St. Louis, CA, USA); ERK, phospho-ERK (p-ERK)and adiponectin (\#4695S, \#4370Sand \#2789S, Cell Signaling, Beverly, MA, USA) and aP2 (\#271529, Santa Cruz Biotechnology, Dallas, TX, USA) were used. The ELISA kits detecting proinflammatory cytokines, TNF- $\alpha, \mathrm{MCP}-1$, plasminogen activator inhibitor (PAI), and IL-6 were provided by R\&D Systems (Minneapolis, MN, USA) and IL-1 $\beta$ was provided by Biolegend ${ }^{\circledR}$ (San Diego, CA, USA). The MitoXpress oxygen consumption assay kit (Agilent, CA, USA) was used to detect energy consumption. TRIzol reagent (Ambion, Santa Clara, CA, USA) was used to extract total RNA, and protein assaydye reagent, and Laemmli 4x buffer (BioRad, Hercules, CA, USA) were used. Ponceau S solution (AMRESCO.Inc., Philadelphia, PA, USA), and ECL kit (GE Healthcare, Chicago, IL, USA), and a polymerase chain reaction (PCR) premix (BioNeer, Daejeon, Republic of Korea) were used.

\subsection{Cell Culture}

The mouse embryo 3T3-L1 preadipocytes was purchased from the American Type Culture Collection (ATCC, Manassas, VA, USA). The 3T3-L1 cells were cultured, as previously described $[4,18]$. 3T3-L1 cells were cultured in the regular DMEM including 10\% bovine calf serum(BCS) and $1 \%$ penicillin-streptomycin at $37^{\circ} \mathrm{C}$ in a $5 \% \mathrm{CO}_{2}$ incubator for four days. After reaching confluence, the cells were initiated for adipocyte differentiation by incubation in the DMEM ( $\mathrm{NaCl} 75 \mathrm{mM})$ of growth medium supplemented with $10 \%$ FBS, 1\% penicillin-streptomycin, $1 \mathrm{uM}$ DEX, $500 \mu \mathrm{M}$ IBMX, and $10 \mathrm{ug} / \mathrm{mL}$ insulin, for two days (Days 0-1), followed by culture in growth medium supplemented with insulin $(10 \mathrm{ug} / \mathrm{mL})$. According to the standard protocol, the 3T3-L1 cells are differentiated to white adipocytes on Day 8 and the medium was changed every 2 days.

\subsection{Beiging and MEK6 Overexpression in 3T3-L1 Cells}

For the beiging process, $50 \mathrm{nM}$ triiodotyronine $\left(\mathrm{T}_{3}\right)$ was added into the growth medium for 2 days, and the medium for beiging (10\% FBS-DMEM, $10 \mathrm{ug} / \mathrm{mL}$ insulin, $0.5 \mathrm{uM}$ IBMX, $50 \mathrm{nM} \mathrm{T}$, and1 uM rosiglitazone) was changed every 2 days for 8 days. BLA 
was confirmed by UCP-1 protein expression [19]. For the MEK6 transfection, MEK6 DNA (NM_011943) mouse tagged ORF Clone (MG204942, Origene, Rockville, MD, USA) was transfected in the competent bacteria, and plasmid DNA was isolated by pDNA purification kit (Cosmogentech, Seoul, Republic of Korea). A classic, highly effective method of Lipofectamine 3000 reagent, was used for the MEK6 for over-expression in adipocytes [20]. 3T3-L1 cells ( $3 \times 10^{5}$ cells/well in 6 well-plate) were cultured for $24 \mathrm{~h}$ at $37{ }^{\circ} \mathrm{C}$ in $5 \% \mathrm{CO}_{2}$ until they reached confluence. The DNA mixture was made with Lipofectamine 3000 reagents, p3000 reagent, opti-MEM, and DNA solution. The DNA mixture was activated for $15 \mathrm{~min}$ at room temperature and then dropped in to the 3T3-L1 cells. The cells were incubated for $3-4 \mathrm{~h}$ at $37^{\circ} \mathrm{C}$ in $5 \% \mathrm{CO}_{2}$. After activation, antibiotics free medium was added to the cells; before culturing them under the same conditions. Transfection of MEK6 was confirmed by the mRNA(real-time PCR) and protein expression (western blotting).

\subsection{Cell Viability Assay and Sodium Chloride ( $\mathrm{NaCl}$; Salt) Treatment}

The concentration of salt $(\mathrm{NaCl})$ to use was determined by the MTT assay. Sodium chloride was diluted to $0 \mathrm{mM}, 25 \mathrm{mM}, 50 \mathrm{mM}, 100 \mathrm{mM}, 150 \mathrm{mM}$, and $200 \mathrm{mM}$ with 10\% BCS DMEM(Low-salt; $\mathrm{NaCl} 75 \mathrm{mM}$ ) before being administered to the cells for $24 \mathrm{~h}$. After removal of $\mathrm{NaCl}$ in the medium, $10 \% \mathrm{MTT}$ assay reagent was poured onto the 3T3-L1 cells, and the cells were incubated for $2 \mathrm{~h}$ at $37{ }^{\circ} \mathrm{C}$ in $5 \% \mathrm{CO}_{2}$. The MTT assay reagent was removed, and then DMSO was added; the plates were then placed on a shaker for $30 \mathrm{~min}$ at room temperature. The absorbance at $590 \mathrm{~nm}$ and $650 \mathrm{~nm}$ was detected with a plate reader (Thermofisher).

\subsection{Oil Red O Staining(ORO)and DAPI/Nile Red Staining}

The amount of lipid accumulation was confirmed by ORO staining on Day 8. After washing twice with $1 \times$ PBS, the cells were fixed in $4 \%$ para-formaldehyde for one hour. The fixing solution was then washed away with $1 \times$ PBS and the cells were dried thoroughly. $10 \%$ ORO solution was used to stain the lipid droplet of 3T3-L1 cells for 20 min, before they were washed with $1 \times$ PBS three times. We monitored the stained cells with a microscope. After removing the medium and washing with $1 \times$ PBS, the cells were fixed in $4 \%$ paraformaldehyde for $10 \mathrm{~min}$. The cells were washed three times with $1 \times$ PBS to remove the fixing solution. Nile red and BODIPY solution were diluted 1: 2000 and 1:1000 in $1 \times$ PBS, and then added to the cells for staining at room temperature for $15 \mathrm{~min}$. After washing three times for $5 \mathrm{~min}$, we stained the cell nuclei with diluted DAPI solution at room temperature for $30 \mathrm{~min}$. After washing away the DAPI solution with $1 \times$ PBS three times for $5 \mathrm{~min}$, each sample was wet-mounted and observed under $400 \times$ magnification with a confocal laser scanning microscope (ZEISS, Oberkochen, Germany).

\subsection{Real-Time PCR(RT-PCR) and Western Blotting Analysis}

Total RNA was extracted by TRIzol reagent and RNA concentration was measured by Nano-drop 2000 spectrometer (Thermofisher, MA, USA). cDNA was synthesized from mRNA and amplified using a CFX Connect real-time system (Bio-Rad Laboratories). Primers were designed with Primer-BLAST: MEK6 (forward: 5'-TGGTGGAGA AGATGC GTCACGT-3', reverse: 5'-GTCACGGTGAATGGACAGTCCA-3') and glyceraldehyde-3phosphate dehydrogenase (forward: 5'-CGTGCCGCCTGGAGAAACC-3', reverse: 5' TGGAAGAGTGGGAGTTGCTGTTG-3').

The Bradford assay was used to determine the protein concentrations. Total protein extracts of cells were isolated and separated on 10\% SDS-PAGE gel and transferred the membrane, which were then blocked and incubated with primary antibodies. The method for western blotting with 1st and 2nd antibodies for each target proteins was followed by the general protocols. The protein expression was detected by using the ECL system (GE Healthcare, Chicago, IL, USA) and Chemidoc system (BioRad, CA, USA). 


\subsection{ELISA Assay}

The ELISA MAX ${ }^{\mathrm{TM}}$ set kit for each inflammatory cytokine factor was purchased from Biolegend (San Diego, CA, USA). For the ELISA assay, $1 \mathrm{~mL}$ of supernatant was collected on Day 8. The ELISA was performed with the standard method provided by the manufacturer. (Details: The capture antibody was diluted 1:200 in $100 \mathrm{uL}$; of diluent sol A capture antibody solution, which was added to each well of the 96 well ELISA plate. The plate was incubated at room temperature overnight.)

\subsection{Oxygen Consumption (Energy Consumption) Assay}

To determine the energy expenditure in $\mathrm{Tg}^{(-/-)}$and $\mathrm{Tg}^{(+/+)}$with salt-treated WAT and BLA, oxygen $\left(\mathrm{O}_{2}\right)$ consumption $(\mathrm{RFU} / \mathrm{h})$ in the respiratory system of mitochondria in differentiated and live adipocytes was measured by the Mito Xpress pH-Xtra data visualization tool system (Agilent, Santa Clara, CA, USA) [19].The working solution was prepared by diluting the medium with Xpress agent at a 1:9 ratio. After the differentiation, the cells were incubated with the working solution and two drops of HS mineral oil per well to block the $\mathrm{O}_{2}$ in flow from the medium. Absorbance was measured at 380 and $650 \mathrm{~nm}$ using a fluorescence plate reader (Molecular Devices), and the $\mathrm{O}_{2}$ consumption rate was recorded every $17 \mathrm{sec}$ for a total of $100 \mathrm{~min}$. We collected the data at two points during the experiments, such as at the inflection points of the curve (almost at $30 \mathrm{~min}$ from the beginning), and at the end points.

\subsection{Statistical Analysis}

All experiments were performed in triplicate and the data are expressed as the mean \pm standard deviation (SD). Comparison of two or more groups was performed by Student's t-test or one-way analysis of variance (ANOVA) with Duncan's multiple range test. (IBM SPSS Statistics SW, Ver22). Differences were considered to be statistically significant at $p<0.05$ and were described by superscript letters (a, b, c, d).

\section{Results}

\subsection{Salt Treatment, and Characteristics of Beiging and MEK6 Transfection}

Cell viability (MTT assay) was dose-dependently increased until $50 \mathrm{mM}$ and decreased above $100 \mathrm{mM}, 50 \mathrm{mM}$ was determined to be a suitable concentration without toxicity. (Figure 1A) In the pilot study, we found TG accumulation and MAPK/ERK expression were dose-dependently increased until $\mathrm{NaCl} 100 \mathrm{mM}$ without morphologic damage [4]. After MEK6 was transfected into WAT, we confirmed that the MEK6 mRNA in the $\mathrm{Tg}^{(+/+)}$ group was increased by 2.5 times, compared to that in the $\mathrm{Tg}^{(-/-)}$, and $M E K 6$ transfected WAT were also differentiated in the $\mathrm{Tg}^{(-/-)}$group. The MEK6 protein and MEK6-related phospho-ERK/ERK saw 3.5 and 1.5 times increases in $\mathrm{Tg}^{(+/+)}$WAT compared to $\mathrm{Tg}^{(-/-)}$. (Figure 1B) Not only MEK6 expression but also MAPK pathways activation was also confirmed in the MEK6 transfected cells. The expression of beiging biomarker, UCP-1, in BLA was a double that in WAT, and we found that MEK6 expression in BLA was $50 \%$ lower than WAT. (Figure 1D) We also confirmed that MEK6 transfection induced the adipogenic factors, PPAR- $\gamma, \mathrm{C} / \mathrm{EBP}-\alpha$, and aP2 proteins by 4 -fold, 3-fold, and 1.5-fold, respectively, compared to $\mathrm{Tg}^{(-/-)}$WAT. (Figure 1C,E) Since the adiponectin/leptin ratio was significantly decreased in MEK6-overexpressed WAT, MEK6 transfection may show the same pattern, with the high production of the inflammatory cytokine, leptin or the low production of the anti-inflammatory cytokine, adiponectin. 
A

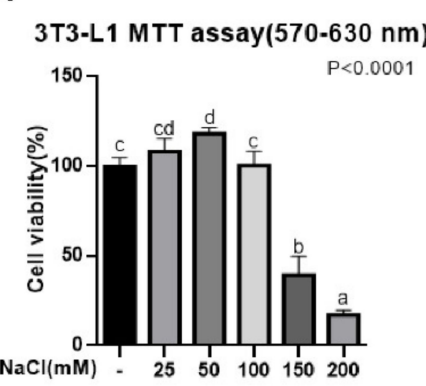

B

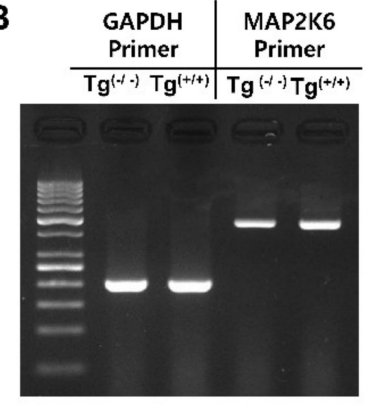

C
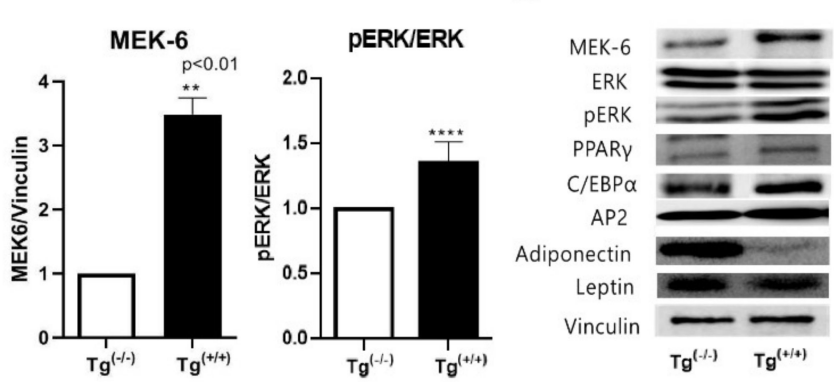

D

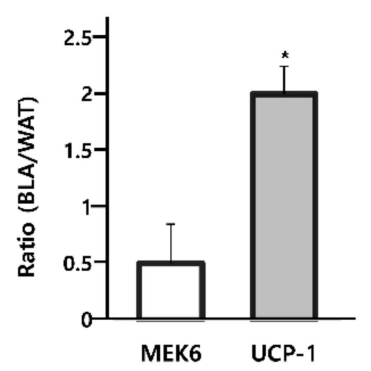

E

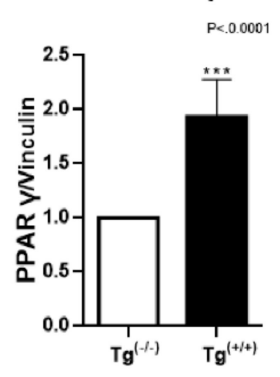

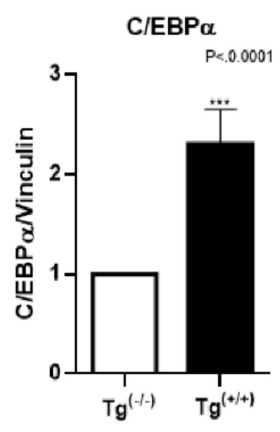

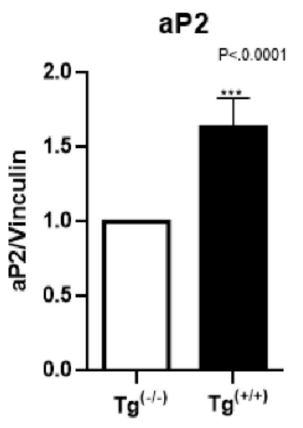

Adiponectin/Leptin ratio

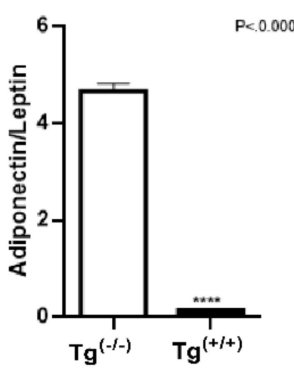

Figure 1. Salt treatment, and characteristics of $M E K 6$ transfection and beiging. (A) Salt treatment level ( $\mathrm{NaCl} 50 \mathrm{mM})$ was determined by cell proliferation assay. Different superscript letters $(a, b, c, d)$ indicate the significant differences by ANOVA test $(p<0.05)$. (B) MEK6-transfected adipocytes were confirmed by mRNA and protein levels. (C) The expression of proteins related to MEK6 transfection compared to non-transfection. (D) The beiging of WAT(BLA) was confirmed by UCP-1 expression and MEK6 was depressed in BLA. (E) Adipogenesis biomarkers, PPAR- $\gamma$, CEBP- $\alpha$, aP2 and adiponection/leptin ratio, were increased in MEK6 transfected WAT. Significant differences in individual treatments versus controls were determined by unpaired $t$-test. * $p<0.05,{ }^{* *} ; p<0.01{ }^{* * *} ; p<0.001,{ }^{* * * *} ; p<0.0001$.

\subsection{Beiging Modulates Salt Treated-and MEK6 Transfected-Adipogenesis}

According to the ORO and DAPI/Nile red staining, the cell sizes and numbers of fat cells were increased in both salt-treated $\mathrm{Tg}^{(+/)}$and $\mathrm{Tg}^{(-/-)}$compared to non-salted cells, but the beiging process reduced salt-induced fat accumulation. (Figure 2A) The adipogenic effect of salt in the $\mathrm{Tg}^{(+/+)}$group was also reduced under the beiging process compared to in $\mathrm{Tg}^{(-/-)}$group. To determine the combined effects of salt and MEK6 transfection in WAT and BLA, we compared all of the adipogenesis and beiging related factors between the MEK6 transfected and control cells. In WAT, the protein expression of adipogenesis related factors such as MEK6, PPAR- $\gamma$, and C/EBP- $\alpha$ was increased in salt-treated cells, and this pattern was strengthened in $\mathrm{Tg}^{(+/+)}$to a greater extent than $\mathrm{Tg}^{(-/-)}$. (Figure 2B-E) In both salt-treated \& MEK6-transfected WAT, the highly expressed proteins of MEK6 and PPAR- $\gamma$ were strongly decreased in BLA by $50 \%$ compared to in WAT. MEK6 and PPAR- $\gamma$ were increased only by MEK6 transfection in BLA, but salt did not change them in BLA. However, $\mathrm{C} / \mathrm{EBP}-\alpha$ protein was significantly depressed in salt treated- and MEK6-transfeced BLA, unlike the patterns of MEK6 and PPAR- $\gamma$. (Figure 2B-E) We concluded that both salt and the MEK6 transfection affected adipogenesis in WAT, but MEK6 gene, not salt, was the adipogenic factor in BLA.

\subsection{Beiging Reduces Salt- and MEK6 Gene-Induced Inflammatory Adipocytokines}

Based on the ELISA data, we concluded that the production of pro-inflmmatory and adipocyte-derived cytokines, TNF- $\alpha$ and IL-1 $\beta$, was increased almost 3 to 5 -fold by MEK6 transfection in WAT, and this pattern was further strengthened in the salt-treated $\mathrm{Tg}^{(+/+)}$ groups. (Figure 3) Monocyte chemoattractant protein-1 (MCP-1) was not changed in $\mathrm{Tg}^{(+/+)}$ compared to $\mathrm{Tg}^{(-/-)}$, nor was plasminogen activator inhibitor-1 (PAI-1) or CD14 affected. (data not shown) IL-6 was increased by 4 -fold by both salt treatment and MEK6 transfection 
compare to in non-salted $\mathrm{Tg}^{(-/-)}$, and salt did not change IL-6 expression in $\mathrm{Tg}^{(-/-)}$. Since IL-6 is an interleukin that has both a pro-inflmmatory and anti-inflammatory characteristics, it reacted to salt and MEK 6 transfection. However, the levels of IL- $1 \beta$, TNF- $\alpha$ and IL- 6 were decreased by $90 \%, 50 \%$, and $60 \%$, respectively in salt treated- and MEK6 transfected BLA compared to the same conditions of WAT, but MCP- 1 was only increased in $\mathrm{Tg}^{(+/+)}$BLA compared to WAT. We concluded that MEK6 might be involved triggering or activating inflammatory metabolism during the differentiation of adipocytes but beiging positively reduced the synergistic effects of salt and MEK6 on inflammation.

\section{4. $\mathrm{O}_{2}$ Consumption in WAT and BLA with Salt Treatment \& MEK6 Transfection}

We also confirmed that the beiging biomarker, UCP-1 expression, was not changed in WAT by neither salt or MEK6 transfection; however, UCP-1 was increased by 2-fold in BLA compared to WAT. UCP-1 expression was significantly decreased in BLA as salt treatment, and MEK6 transfection, unlike in WAT. (Figure 4A) Since the $\mathrm{O}_{2}$ consumption at the end points almost converged in a parabola around 45 to $50 \mathrm{RFU} / \mathrm{h}$, the threshold points of the curve, at which $\mathrm{O}_{2}$ consumption suddenly changed, were compared. At the threshold points of the curve of $\mathrm{O}_{2}$ consumption intensity, salt treatment decreased $\mathrm{O}_{2}$ consumption in WAT compared to non-salt with $\mathrm{Tg}^{(-/-)}$. However, this increased with $\mathrm{Tg}^{(+/+)}$was maximized up to three times in the interaction with salt and MEK6 transfection in WAT. We found that the MEK6 gene had a stronger effect on the $\mathrm{O}_{2}$ consumption than in the control. Without MEK6 transfection, $\mathrm{O}_{2}$ consumption was higher in BLA and salt-treated BLA than the WAT control. However, the highest intensity (RFU/h) in WAT with synergistic effects of salt and MEK6 transfection was significantly reduced by 50\% in BLA. MEK6 transfection increased $\mathrm{O}_{2}$ consumption at threshold points in both WAT and BLA; moreover, it made the time to reach maximal $\mathrm{O}_{2}$ consumption shorter in BLA (data not shown). Therfore, beiging increased thermogenesis instead of through ATP production in mitochondria, even though both salt treatment and $M E K 6$ transfection were involved in significant factors related to anabolism.

A

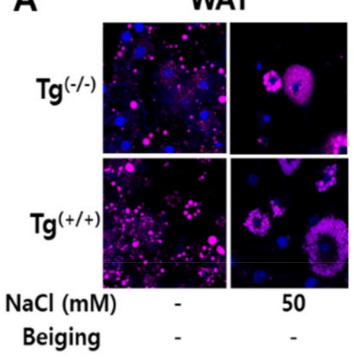

D

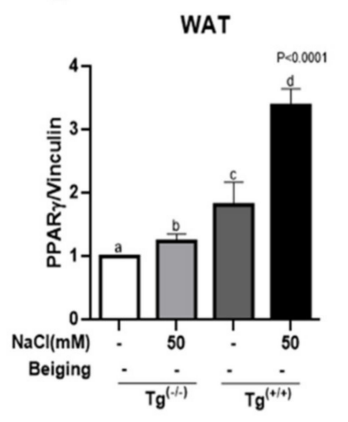

BLA

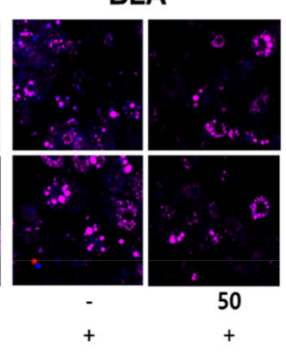

BLA

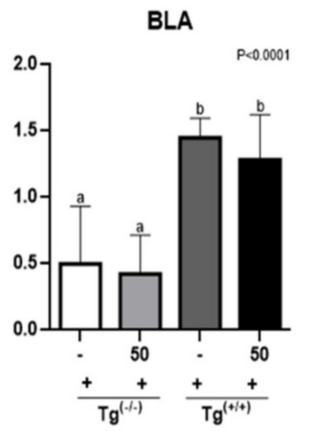

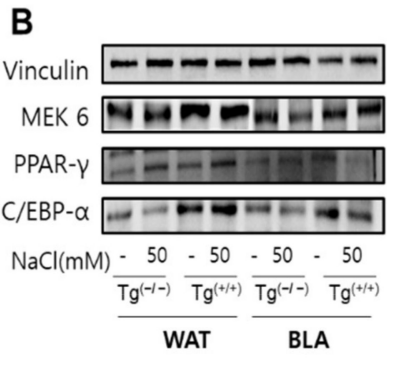

E

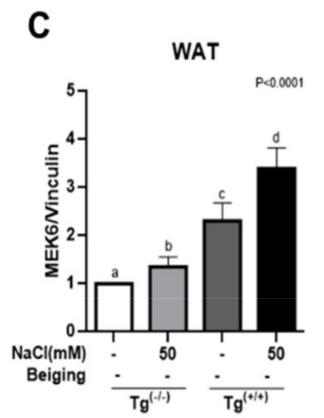

BLA

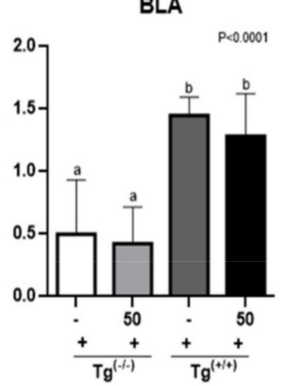

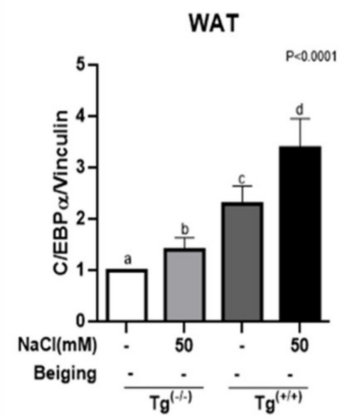

BLA

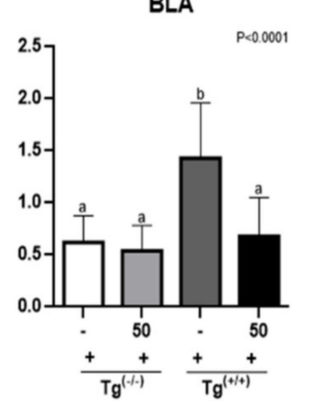

Figure 2. Beiging modulates salt treatment and MEK6 transfection-induced adipogenesis. Synergistic interaction between salt and MEK6 transfection affecting fat accumulation (DAPI/Nile red staining; (A) according to MEK6 expression (B,C), and protein expression related to adipogenesis (B-E) in WAT, but all effects were weakened by the beiging process. Different superscript letters $(a, b, c, d)$ in individual treatments in WAT or BLA indicate the significant differences from ANOVA test. 

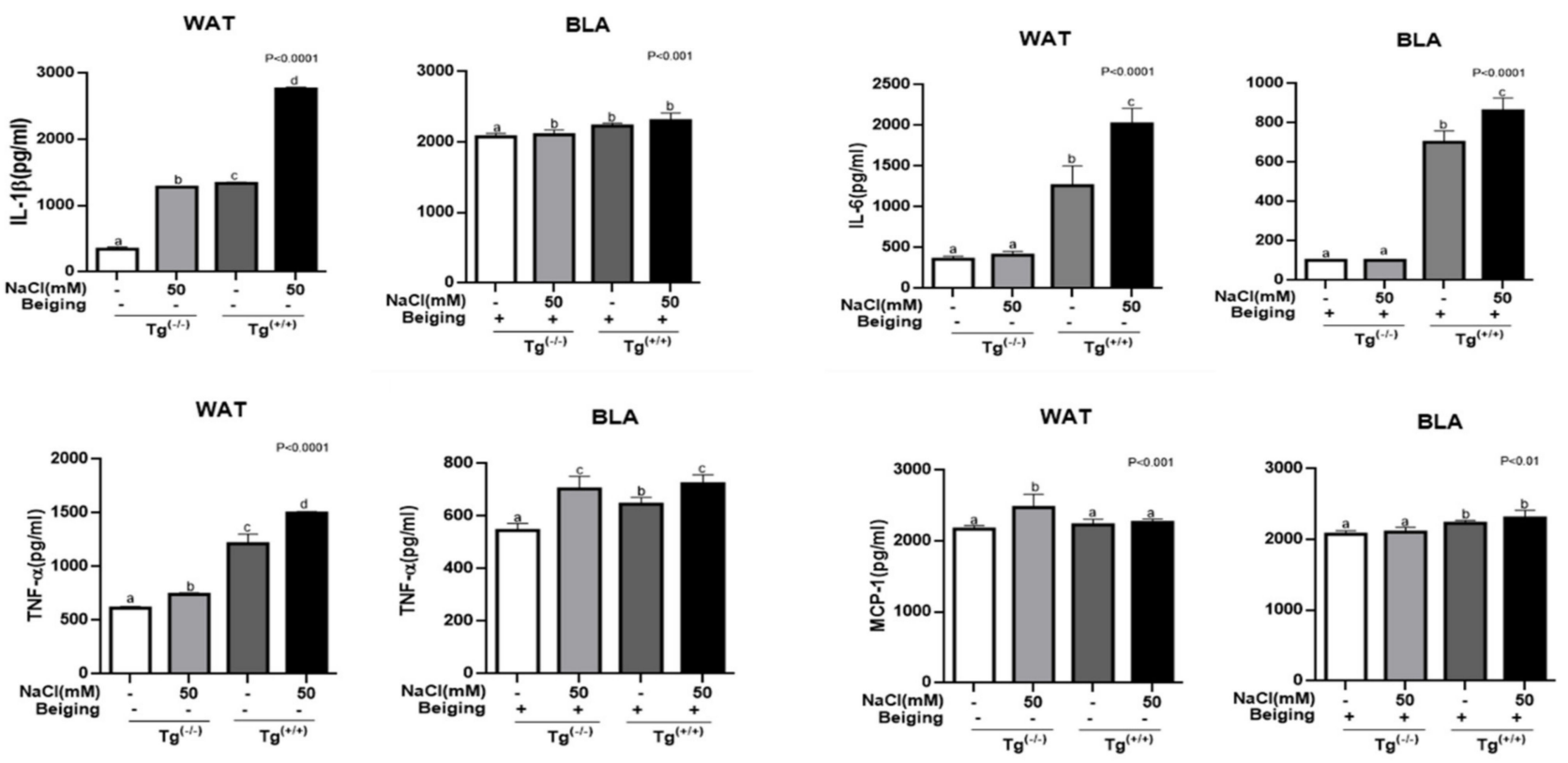

Figure 3. Beiging positively reduced the interactive effects of salt and the MEK6 gene on the production of inflammatory cytokines, such as TNF-alpha, IL-beta and IL-6, in WAT. Significant differences in individual treatments of WAT or BLA are indicated by ANOVA test with different superscript letters (a, b, c, d).

A

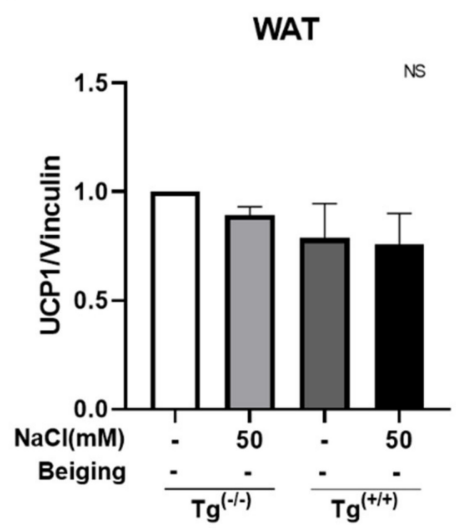

BLA

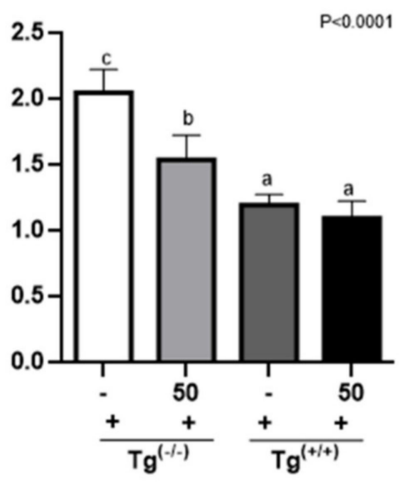

B

Figure 4. Beiging biomarker, UCP-1, was increased in BLA, but it was decreased by salt treatment and MEK6 transfection. (A) Oxygen consumption intensity $(\mathrm{RFU} / \mathrm{h})$ in salt treated-WAT and BLA with $\mathrm{Tg}^{(+/+)}$and without $\mathrm{Tg}^{(+/+)}$were measured at the time of an inflection point of curve in 8th day-culture when cells were completely differentiated and alive. (B) Significant differences for individual treatments versus controls are indicated by ANOVA test with different superscript letters letters (a, b, c, d). (NS; non significance).

\section{Discussion}

This study is the first to show that the beiging process reduced the synergistic effects of salt- and the MEK6 gene in obesity. With two pilot studies that salt and MEK6 gene were involved in fat accumulation, we found that beiging (BLA) reduced salt-and MEK6 transfection-induced adipogenesis, and production of inflammatory adipocytokines [4,13].

MAPK/ERK pathways are associated with expression of genes involved in adipogenesis, such as insulin resistance, oxidative stress and inflammation [4,21-23]. MAPKs and ERK-induced fat synthesis was immediately activated to a great extent after PPAR- $\gamma$ and C/EBP- $\alpha$ were expressed in WAT [24]. In ERK KO mice, the sizes, numbers, and total weights of WAT were decreased compared to those in the control because ERK may inhibit the active form of phosphorylated PPAR- $\gamma$ [21]. However, we focused that obesity 
results in a chronic low-grade inflammatory state, with increased pro-inflammatory cytokines, TNF- $\alpha$ and IL-6, causing the activation of stress-induced MAPK signaling $[25,26]$. Chi et al. reported that MAPK is negatively regulated by MAPK phosphatases and proinflammatory factors, TNF- $\alpha$ and IL-6, were highly detrimental to MAPK phosphatase deficient mice [27]. Moreover, IL-6 acted as a pro-inflammatory molecule in this study because it resulted in the a same pattern of increasing TNF- $\alpha$ and IL- $1 \beta$ with salt- and MEK6 transfection. In the pilot study, we found that the crosstalk among the signaling pathways of MAPK/ERK, Akt-mTOR, and the inflammatory adipogenesis could be the possible mechanism of salt-linked obesity, similarly to in other studies [4,5,28-30]. Salt-loading diets ( $>15 \mathrm{~g} \mathrm{NaCl} /$ day for seven days)led to consistent hypoxia and the suppression of the circulating renin-angiotensin-aldosterone system, as well as monocyte pro- inflammatory activation [5].

To induce browning, $\mathrm{T}_{3}$ is one of the regulators of transcription factors in thermogenesis and mitochondrial function, and rosiglitazone may promote the adrenergic increase in UCP-1, and insulin, as a stimulator of glucose uptake into fat cells [10,30-32]. Din et al. found the 52 genes that correlated with UCP-1 in BAT that were involved in the causal relationship between lipid metabolism and a carbohydrate-rich meal triggers human BAT thermogenesis [33,34]. MEK6 was not involved with any of the 52 genes, but MEK6 expression was reduced by 50\% in BLA while UCP-1 showed a two-fold increase in this study. BAT increases energy expenditure, particularly from glucose in vivo model; however, the metabolic energy rate for fat metabolism was lower in BAT than in the WAT [31]. Sidossis et al. showed that subcutaneous WAT adopts a more thermogenic phenotype after prolonged stress in the burned patients, and browning of WAT was associated with increased whole body metabolic rate [35]. Matesanz et al. proved that browning, $\mathrm{T}_{3}$ mediated UCP-1 induction, increased energy expenditure in mice lacking $M K K 6$, which protects from high fat diet-induced obesity [15]. Since $\mathrm{O}_{2}$ consumption was three times higher in $\mathrm{Tg}^{(+/+)}$groups compared to $\mathrm{Tg}^{(-/-)}$groups over time, the energy demands for fat synthesis in either salt- or MEK6-induced adipocytes were increased.

The $\mathrm{O}_{2}$ consumption in BLA was higher than that in WAT, but $\mathrm{O}_{2}$ consumption in adipocytes depends on meal types as well as exposure temperature [33,34]. In pyruvate kinase $\mathrm{KO}$ mice, since the substrates in the media to be taken up in WAT and BLA are identical, salt and the MEK6 gene are considered the regulators of $\mathrm{O}_{2}$ consumption or energy expenditure in WAT and BLA. The metabolic rate for thermogenesis in mitochondria was higher in BLA to enhance energy expenditure and prevent fat accumulation compared to the preferential ATP production in WAT $[8,36]$. We also found that the time taken for maximal $\mathrm{O}_{2}$ consumption was delayed in the transfected groups compared to that in the non-transfected group, and it takes time for the connection between MEK6 and trigger factors, such as glucose transporter 1 or 4 , to affect the maximal $\mathrm{O}_{2}$ consumption [35].

To address the limitations of this study, we are planning an in vitro study to elucidate whether browning reduces diet-induced adipogenesis and inflammation in MEK6 overexpressing mice. However, this first report, that beiging has a complementary effect on the interaction between salt- and MEK6 gene-induced adipogenesis, will contribute to the obesity research. Although we did not elucidate the mechanisms of MEK6's effects on energy balance during browning, we concluded the MEK6 pathways are a possible mechanism inducing obesity in a person who has high salt intake. With further clinical trials, these preventive effects on obesity might be more substantial in the future.

Author Contributions: For research article, our authors contributed as followings; conceptualization and funding acquisition, M.L.; methodology, experiments and data analysis, S.K. Both authors have read and agreed to the published version of the manuscript.

Funding: This study was funded by a grant from the Korean Health Technology R\&D project, Ministry of Health \&Welfare, Republic of Korea (grant number: HI17C0863), and the National Research Foundation of the Korean government (grant number: 2019R1A2C1008434).

Institutional Review Board Statement: Not applicable. 
Informed Consent Statement: Not applicable.

Data Availability Statement: Not applicable.

Conflicts of Interest: The authors declare no conflict of interest.

\section{References}

1. Ritchie, S.A.; Connel, J.M.C. The link between abdominal obesity, metabolic syndrome and cardiovascular disease. NMCD 2007, 17, 316-326. [CrossRef]

2. Alberti, K.G.; Zimmet, P.; Shaw, J. The metabolic syndrome-A new worldwide definition. Lancet 2005, 366, 1059-1062. [CrossRef]

3. Jung, J.H.; Lee, M. Effects of interaction between SLC12A3 polymorphism, salt-sensitive gene, and $\mathrm{NaCl}$ intake on risk of child obesity. J. Nutr. Health 2017, 50, 32-40. [CrossRef]

4. Lee, M.; Sorn, S.R.; Lee, Y.; Kang, I. Salt induces adipogenesis/lipogenesis and inflammatory adipocytokines secretion in adipocytes. Int. J. Mol. Sci. 2019, 20, 160. [CrossRef]

5. Zhou, X.; Yuan, F.; Ji, W.; Guo, Z.Z.; Zhang, L.; Lu, R.Y.; Liu, X.; Liu, H.M.; Zhang, W.C.; Jiang, T.M.; et al. High-salt intake induced visceral adipose tissue hypoxia and its association with circulating monocyte subsets in humans. Obesity 2014, 22, 1470-1476. [CrossRef]

6. Lydon, R.; McAnena, L.; Livingstone, M.B.E.; Kerr, M.A. The association between salt intake and obesity in UK adults aged 19-64 years. Proc. Nutr. Soc. 2016, 75, E206. [CrossRef]

7. Cannon, B.; Nedergaard, J. Brown Adipose Tissue: Function and Physiological Significance. Physiol. Rev. 2004, 84, 1-83. [CrossRef] [PubMed]

8. Morrison, S.; McGee, S.L. 3T3-L1 adipocyte display phenotypic characteristics of multiple adipocytes lineages. Adipocyte 2015, 4, 295-302. [CrossRef]

9. Ibarra, Z.L.; Modrego, J.; Valero-Muñoz, M.; Rodríguez-Sierra, P.; Zamorano-León, J.J.; González-Cantalapiedra, A.; de las Heras, N.; Ballesteros, S.; Lahera, V.; López-Farré, A. Metabolic differences between white and brown fat from fasting rabbits at physiological temperature. J. Mol. Endocrinol. 2015, 54, 105-113. [CrossRef] [PubMed]

10. Asano, H.; Kanamori, Y.; Higurashi, S.; Nara, T.; Kato, K.; Matsui, T.; Funaba, M. Induction of Beige-Like adipocytes in 3T3-L1 cells. J. Vet. Med. Sci. 2013, 76, 57-62. [CrossRef]

11. Lee, J.Y.; Takahashi, N.; Yasubuchi, M.; Kim, Y.I.; Hashizaki, H.; Kim, M.J.; Sakamoto, T.; Kawada, T. Triiodothyronine induces UCP-1 expression and mitochondrial biogenesis in human adipocytes. Am. J. Physiol. Cell Physiol. 2012, 302, 463-472. [CrossRef]

12. Guerra, C.; Koza, R.A.; Yamashita, H.; Walsh, K.; Kozak, L.P. Emergence of brown adipocytes in white fat in mice is under genetic control. Effects on body weight and adiposity. J. Clin. Investig. 1998, 102, 412-420. [CrossRef]

13. Lee, M.; Lee, Y.; Kang, I.; Shin, J.E.; Sorn, S.R. RMR-Related MAP2K6 Gene Variation on the Risk of Overweight/Obesity in Children: A 3-Year Panel Study. J. Pers. Med. 2021, 11, 91. [CrossRef]

14. Zhang, Y.; Li, R.; Meng, Y.; Li, S.; Donelan, W.; Zhao, Y.; Qi, L.; Zhang, M.; Wang, X.; Cui, T.; et al. Irisin stimulates browning of white adipocytes through mitogen-activated protein kinase p38 MAP kinase and ERK MAP kinase signaling. Diabetes 2014, 63, 514-525. [CrossRef] [PubMed]

15. Matesanz, N.; Bernardo, E.; Acín-Pérez, R.; Manieri, E.; Sieira, S.P.; Hernández-Cosido, L.; Montalvo-Romeral, V.; Mora, A.; Rodriguez, E.; Leiva-Vega, L.; et al. MKK6 controls T3-mediated browning of white adipose tissue. Nat. Commun. $2017,8,856$. [CrossRef] [PubMed]

16. Lee, M.J.; Park, M.; Kim, J.H.; Sung, S.Y.; Lee, M. Impacts of High NaCl Intake on Obesity-related Gene Expression. J. East Asian Soc. Diet. Life 2018, 28, 364-374. [CrossRef]

17. Lee, M.; Kim, M.K.; Kim, S.M.; Park, H.; Park, C.G.; Park, H.K. Gender-Based differences on the association between salt-sensitive genes and obesity in Korean children aged between 8 and 9 years. PLoS ONE 2015. [CrossRef]

18. Fusishrio, M.; Goto, Y.; Katagiri, H.; Sakoda, H.; Ogihara, T.; Anai, M.; Onishi, Y.; Ono, H.; Abe, M.; Shojima, N.; et al. Three mitogen-activated protein kinases inhibit insulin signaling by different mechanisms in 3T3-L1 adipocytes. Mol. Endocrinol. 2003, 17, 487-497.

19. Lee, M.; Lee, M. The Effects of C3G and D3G Anthocyanin-Rich Black Soybean on Energy Metabolism in Beige-like. Adipocytes. J. Agric. Food Chem. 2020, 68, 12011-12018. [CrossRef] [PubMed]

20. Manieri1, E.; Sabio, G. Stress kinases in the modulation of metabolism and energy balance. J. Mol. Endocrinol. 2015, 55, R11-R22. [CrossRef]

21. Prusty, D.; Park, B.H.; Davis, K.E.; Farmer, S.R. Activation of MEK/ERK signaling promotes adipogenesis by enhancing peroxisome proliferator-activated receptor gamma (PPAR gamma) and C/EBPalpha gene expression during the differentiation of 3T3-L1 preadipocytes. J. Biol. Chem. 2002, 277, 46226-46232. [CrossRef]

22. Bost, F.; Aouadi, M.; Caron, L.; Even, P.; Belmonte, N.; Prot, M.; Dani, C.; Horman, P.; Pages, G.; Pouyssegur, J.; et al. The extracellular signal regulated kinase isofor $\mathrm{m}$ ERK1 is specifically required for in vitro and in vivo adipogenesis. Diabetes 2005, 54, 402-411. [CrossRef]

23. Fost, F.; Aouadi, M.; Caron, L.; Binetruy, B. The role of MAPKs in adipocyte differentiation and obesity. Biochimie 2005, 87, 51-56.

24. Gehart, H.; Kumpf, S.; Ittner, A.; Ricci, R. MAPK signalling in cellular metabolism: Stress or wellness? EMBO 2010, 11, 834-840. [CrossRef] [PubMed] 
25. Rahimi, P.; Mobarakeh, I.V.; Kamalzare, S.; SajadianFard, F.; Vahabpour, R.; Zabihollahi, R. Comparison of transfection efficiency of polymer-based and lipid-based transfection reagents. Bratisl. Med. J. 2018, 119, 701-705. [CrossRef] [PubMed]

26. Sabio, G.; Davis, R.J. TNF and MAP kinase signaling pathways. Semin. Immunol. 2014, 26, 237-245. [CrossRef] [PubMed]

27. Chi, H.; Barry, A.P.; Roth, R.J.; Wu, J.J.; Jones, E.A.; Bennett, A.M.; Flavell, R.A. Dynamic regulation of pro- and anti-inflammatory cytokines by MAPK phosphatese1(MKP-1) in innate immune responses. Proc. Natl. Acad. Sci. USA 2006, 103, 2274-2279. [CrossRef]

28. Cox, C.L.; Stanhope, K.L.; Schwaz, J.M.; Graham, J.L.; Hather, B.; Griffin, S.C.; Bremer, A.A.; Berglund, L.; McGahan, J.P.; Keim, N.L.; et al. Circulating Concentrations of Monocyte Chemoattractant Protein-1, Plasminogen Activator Inhibitor-1, and Soluble Leukocyte Adhesion Molecule-1 in Overweight/Obese Men and Women Consuming Fructose- or Glucose-Sweetened Beverages for 10 Weeks. J. Clin. Endocrinol. Metab. 2011, 96, E2034-E2038. [CrossRef] [PubMed]

29. Ogihara, T.; Asano, T.; Ando, K.; Chiba, Y.; Sekine, N.; Sakoda, H.; Anai, M.; Onishi, Y.; Fujishiro, M.; Ono, H.; et al. Insulin resistance with enhanced insulin signaling in high-salt diet-fed rats. Diabetes 2001, 50, 573-583. [CrossRef] [PubMed]

30. Seo, M.J.; Lee, Y.J.; Hwang, J.H.; Kim, K.J.; Lee, B.Y. The inhibitory effects of quercetin on obesity and obesity-induced inflammation by regulation of MAPK signaling. J. Nutr. Biochem. 2015, 26, 1308-1316. [CrossRef]

31. Ikeda, K.; Maretich, P.; Kajimura, S. The Common and Distinct Features of Brown and Beige Adipocytes. Trends Endocrinol. Metab. 2018, 29. [CrossRef] [PubMed]

32. Obregon, M.J. Adipose tissues and thyroid hormones. Front. Physiol. 2014, 5, 479. [CrossRef]

33. Din, M.U.; Saari, T.; Raiko, J.; Kudomi, N.; Maurer, S.F.; Lahesmaa, M.; Fromme, T.; Amri, E.Z.; Klingenspor, M.; Solin, O.; et al. Postprandial Oxidative Metabolism of Human Brown Fat Indicates Thermogenesis. Cell Metab. 2018, 28, 207-216. [CrossRef] [PubMed]

34. Winther, S.; Isidor, M.A.; Basse, A.L.; Skjoldborg, N.; Cheung, A.; Quistorff, B.; Hansen, J.B. Restricting glycolysis impairs brown adipocyte glucose and oxygen consumption. Am. J. Physiol. Endocrinol. Metab. 2018, 314, E214-E223. [CrossRef] [PubMed]

35. Sidossis, L.; Kajimura, S. Brown and beige fat in humans: Thermogenic adipocytes that control energy and glucose homeostasis. J. Clin. Investig. 2015, 125, 478-486. [CrossRef]

36. Kajimura, A.; Spiegelman, S.M.; Seale, P. Brown and Beige Fat: Physiological Roles beyond Heat Generation. Cell Metab. 2015, 22, 546-559. [CrossRef] [PubMed] 